\title{
Robotization of business processes of enterprises of housing and communal services
}

\author{
Alexander Sukhorukov ${ }^{1}$, Sergey Eroshkin ${ }^{2, *}$, Philip Vanyurikhin ${ }^{3}$, Sergey Karabahciev ${ }^{3}$, and \\ Ekaterina Bogdanova ${ }^{1}$ \\ ${ }^{1}$ Plekhanov Russian University of Economics, Moscow, Russia \\ ${ }^{2}$ Russian State Social University (RSSU), Moscow, Russia \\ ${ }^{3}$ Peoples' Friendship University of Russia, Moscow, Russia
}

\begin{abstract}
The article analyzes the problems of robotization of business processes in the field of housing utilities of Russia in the formation of the digital economy. It identifies ways of integrating the main types of information management systems for analyzing and evaluating the economic efficiency of such a digital transformation. The possibility of using the digital process model for making sound economic decisions on the robotization of business processes in HCS is considered.
\end{abstract}

\section{Introduction}

\subsection{A Subsection Sample}

The economic mechanism that has emerged today in the sphere of housing and communal services (HCS) does not ensure the effective and reliable operation of utilities, their timely modernization and satisfaction of the growing demands of consumers. Even though various organizational and legal forms of functioning of HCS are currently being actively tested, the updated business processes do not always contribute to improving the efficiency of utilities. At the same time, "digitalization", which has embraced all spheres of economic activity, is seriously changing the economic mechanism in the management of HCS. Moreover, if the past few decades, the development occurred under the trend of automation of projects and business processes, now it is actual partial or complete exclusion from the control chain of processes executed by man. Robotics process automation (PRA) is an automation (robotization) of repetitive business processes by installing software that, with the help of user interfaces, works with applications and components "on top" of the main IT architecture, replicating actions that are traditionally carried out by humans.

Many enterprises are already actively introducing robots into management activities. According to Google analytics, the number of queries in the search engine on the topic "Robotics process automation" increased 30 times more from 2016 to 2018, and this trend is accelerating every month. According to global studies, in the next 5-7 years, the global market of process robotization is expected to grow to $\$ 2.7$ billion annually, with an average annual increase of about $29 \%$. Robotization of business processes will reduce costs by 20

\footnotetext{
* Corresponding author: EroshkinSIu@rgsu.net
} 
$40 \%$ in repeated data processing processes. According to the IRPI, the use of robotization of business processes reduces the costs for employees in offshore divisions by $2 / 3$. [1]

Figure 1 shows the planned investments of most enterprises in the areas of high-tech development to reduce operating costs. RPA is a leader in significant investments among other high-tech areas such as cloud technologies, Internet of things, big data analysis, virtual reality, augmented reality, blockchain, artificial intelligence, automatic drones, unmanned vehicles, etc. At the same time, new RPA solutions often appear at the junction of different areas and technologies, therefore the listed high-tech areas usually interact with projects for robotization of business processes. [2]

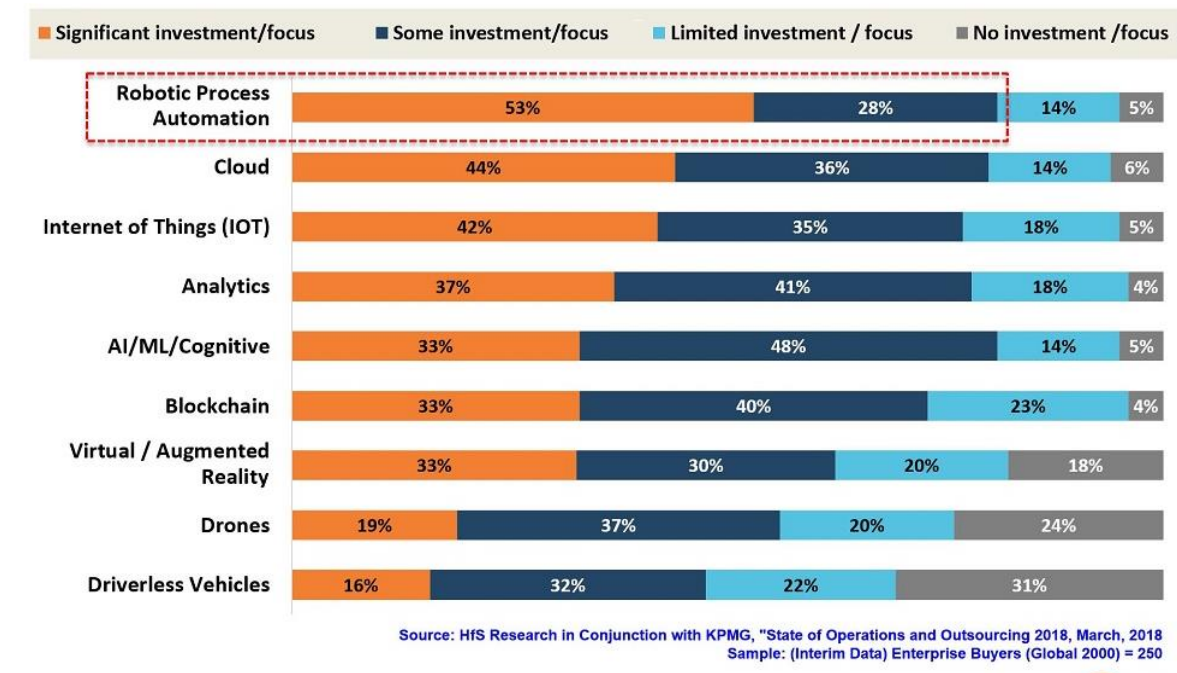

(c) HfS Research 2018

Fig. 1. Planned investments of most enterprises by development areas to reduce operating costs.

Robotization of business processes eliminates errors in operations, increases the reliability and speed of execution of business processes. Compared to the large cost of human time, the machine time is very cheap, the cost of the robotic business process will be small, so most of the stakeholder employees will be unnecessary - they will be replaced by robots.

According to the head of the Center for Strategic Research A. Kudrin, due to the robotization of many business processes in Russia, about a third of the professions may disappear in the next six years. Table 1 shows the professions that, according to Oxford University research, will be replaced by robots in the future. As can be seen from this table 1 , HCS enterprises focused on repetitive business processes may lose a significant portion of their traditional employees.

Table 1. Professions that will eventually be replaced by robots.

\begin{tabular}{|l|c|}
\hline Profession name & Risk \\
\hline Seller by phone & $99.0 \%$ \\
\hline Data entry officer & $98.5 \%$ \\
\hline Junior Associate & $97.6 \%$ \\
\hline Financial analyst & $97.6 \%$ \\
\hline Scaler or Sorter & $97.0 \%$ \\
\hline Financier (other tasks) & $96.8 \%$ \\
\hline Accountant-operator & $95.9 \%$ \\
\hline
\end{tabular}




\begin{tabular}{|l|c|}
\hline $\begin{array}{l}\text { Secretary, leading reception of } \\
\text { visitors }\end{array}$ & $95.6 \%$ \\
\hline lead accountant & $95.3 \%$ \\
\hline
\end{tabular}

It is known that automation and robotization of business using various information systems [3-5] at HCS enterprises occurs when business processes of projects are formalized and logically aligned. If there comes a period when you should use a new developed information model for the development of the company, then reengineering of business processes is carried out, or Japanese practice "Kaizen" is used in the concept of continuous Total Quality Management (TQM). Phased changes in the business of organizations of HCS enterprises through the improvement of activities measured in terms of business processes and their indicators are one of the main development resources in a highly competitive environment. The winner is the one who, using technology, reduces the costs of business processes, while maintaining the greatest value of the product or service for the client.

As a rule, HCS joint-stock enterprises today are formed as a result of removing utility infrastructure (water utilities, thermal power plants, etc.) from the property complex during the privatization of national economy enterprises, or through the incorporation of municipal unitary enterprises (MUE) with the participation of local administrations that Generally, $100 \%$ of the shares of these joint stock companies (JSC). Such transformations affect the business processes created by JSCs. Fig. 2 shows a generalized network of typical top-level business processes for water utilities enterprises. [6] All business processes of water treatment plant are divided into three types: basic, management processes and provide. As a result of the analysis and improvement of these business processes, it is possible to suggest ways of their robotization. However, the cost-effectiveness of such a digital transformation is not obvious.

For example, when robotization of business processes of taking readings from water metering devices, we need an appropriate modern infrastructure. These are Internet portals for entering data by the consumer, and e-mail, and "smart" water accounting devices with independent access to the Internet, and access to the Internet itself, and new software that records and processes readings from "smart" devices.

For example, a robot for taking readings from users from water accounting devices can perform the following list of tasks:

- management information system;

- form transactions to reflect in the account;

- $\quad$ check data quality;

- $\quad$ verify information between the source and target database;

- Inform e-mail managers about the completion of the task.

If the robot accepts readings from "smart" water accounting devices, which themselves transmit data without the participation of the consumer, instead of opening a letter with an attached file and copying information, for example, it immediately processes the data.

Creating an acceptable infrastructure for such an intelligent water accounting system is quite an expensive task and requires an economic justification [7]. This should take into account changes in the current business environment in the field of HCS, modern approaches to information management, concepts of information modeling of the entire life cycle of building objects (building information modeling, BIM) [8], technological features of obtaining information about processes and resources without direct human participation approaches "machine-to-machine communication", "Internet of things", creation of databases with the participation of artificial intelligence in the concepts of "smart home", "smart city", "smart transport", "smart enterprise", etc.

- open a letter with an attached file;

- $\quad$ copy the necessary data from the Internet information portal into specific fields in the 


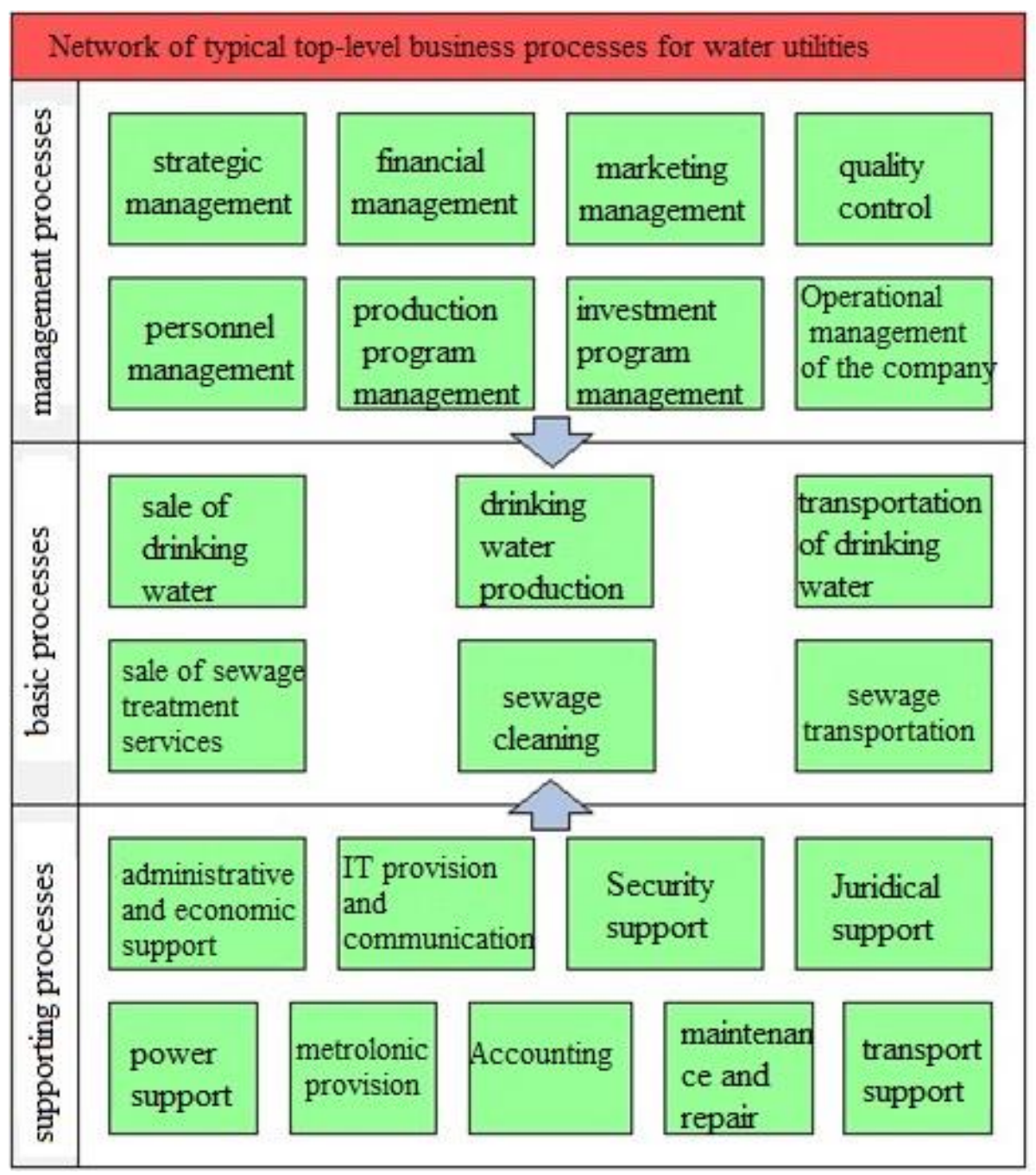

Fig. 2. Generalized network of typical top-level business processes for water utilities enterprises.

To assess the prospects for the introduction of robotization, we need a methodology that takes into account the analysis of the activities of the enterprise HCS with the construction of an operating model of robotization of business processes. Such a methodology should include diagnostics and planning of robotization of business processes at three levels:

- resources (human, informational, technological);

- organizational structure;

- performance of tasks (in the form of policies and regulations, business processes and performance indicators).

Analysis and assessment of the economic efficiency of such a digital transformation of business processes is also conveniently carried out with the help of modern digital tools.

1. For project management robotization of business processes in the field of HCS, you can use PM-systems (Project Management- systems) such as MS Project, Oracle Primavera, etc. However, PM-systems are limited to cascade models of business processes of projects, visualized by a Gantt chart, or by a calendar-network diagram with resources assigned to them in time. In some cases, in such PM-systems, it is possible to implement, for example, 
Scrum and Kanban methodologies, which are also significantly limited in functionality and do not have elements of full-fledged business process modeling.

2. A more detailed financial analysis and evaluation of investment projects for robotization of business processes, considering discounting, can be performed using the ProjectExpert automated business planning program. But it will still be an assessment of the effectiveness of the project.

3. In some cases, you can use the recently popular information modeling technology of the entire BIM life cycle, but they also do not take full advantage of the modeling capabilities of all business processes and are limited only to models of the main business processes visualized and evolved from CAD (computer -aided design) systems [9].

4. For the most detailed analysis of business processes of enterprises of housing and public utilities, you can use BPM (Business Process Modeling) systems with the capabilities of functional, object and simulation modeling. Automation in BPM-systems FTE (Full-Time Equivalent) -labor costs risk ranking, functional cost analysis (FCA), as a process of analysis and budgeting, allowing to evaluate overhead and operating costs of business processes has certain advantages over budgeting, which implemented in PM systems. A systematic approach to the use of existing management automation products [9] will allow in the foreseeable future to implement the ambitious concept of a digital twin - an important component of the digital economy [10].

Consideration of the possibility of improving the business processes of HCS enterprises with the help of BPM-systems with functional, object and simulation capabilities for subsequent robotization becomes a relevant and promising direction, which is fully consistent with the concept of the digital twin.

Now, a digital twin is a software analogue of a physical device that models internal processes, technical characteristics and behavior of a real object under the influence of interference and the environment. An important feature of the digital twin is that the information from the sensors of a real device operating in parallel is used to assign input influences on it. As a private example for HCS enterprises, again, an intellectual water accounting system can be cited.

The basis for modeling water accounting business processes is a BPM system that implements the concept of process management, according to which the strategic goals of an organization implementing project and process approaches are achieved through modeling, execution, monitoring and continuous improvement of business processes executed (see Fig. 3 ). The concept of process management is a significant part of the concept of the digital twin. Detailing business processes depends on the tasks of modeling, but the more detailed the business processes are formalized, the more accurate the digital counterpart will be.

For the synthesis of a complete digital twin, the formalization of all business processes involved in the enterprise's activities, both basic and subsidiary, on which the organization is built with a project-process orientation, is needed. 


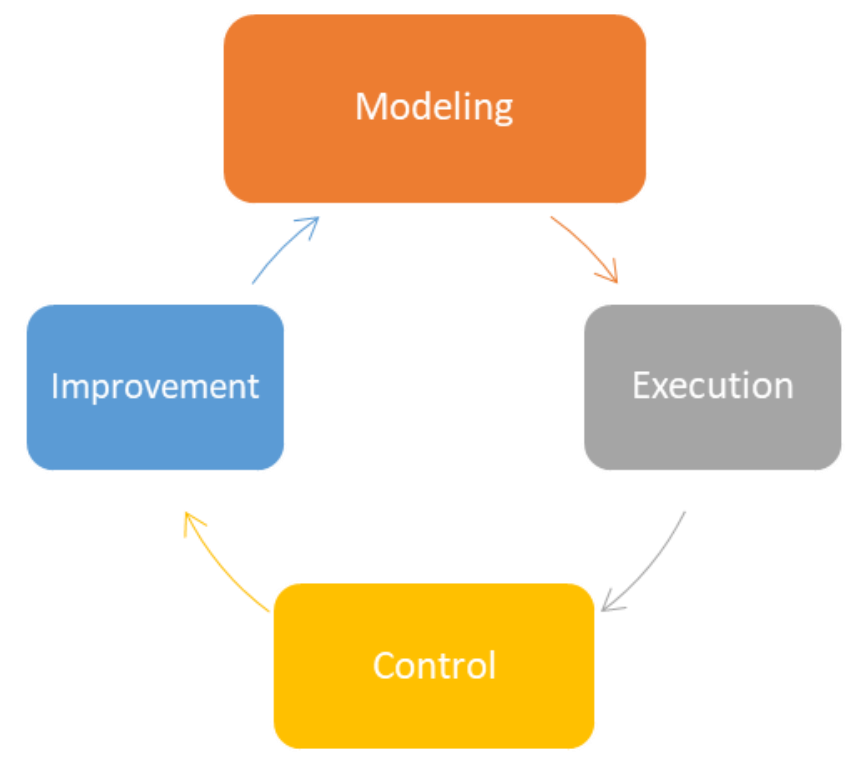

Fig. 3. Process Management Concept.

Various manufacturers of BPM-systems offer their software to the market, which differs in functionality and cost. Building a digital twin based on them will depend on the economic efficiency of using the capabilities of the proposed systems. Therefore, the process of implementing the concept of a digital twin should be gradual with feedback depending on efficiency. Detailing digital twins in business processes should be based on the economic apparatus. In some cases, a general descriptive model of business processes is enough to make the right management decisions, while others will require a detailed simulation model with complex analytical capabilities. In the future, tasks of robotization of business processes will be systematically distributed in tasks of all currently existing management information systems.

\section{References}

1. Robotic Process Automation Market, RPA Industry Report, 2018-2025, https://www.grandviewresearch.com/industry-analysis/robotic-process-automation-rpamarket

2. HfS Research in Conjunction with KPMG "State of Operations and Outsourcing 2018"

3. D. Budiyanto, D.B. Setyohadi, 2017 5th International Conference on Cyber and IT Service Management, CITSM 2017 (2017)

4. F.E. Palominos, C.A. Duran, F.M. Córdova, 2018 7th International Conference on Computers Communications and Control, ICCCC 2018 - Proceedings, 17-22 (2018)

5. A.I. Sukhorukov, G. Shuhong, N.D. Koryagin, S.Y. Eroshkin, 2018 Eleventh International Conference "Management of large-scale system development", MLSD, 14 (2018)doi: 10.1109/MLSD.2018.8551859

6. H. Gaitán Bolaños, Acosta V.J. Ruiz, J. Gabalán Coello, F.E. Vásquez Rizo, Relationship between organizational knowledge variables and the result of organizational objectives in a manufacturing company (Espacios, 2018) 
7. C.A. Duran, F.E. Palominos, 2018 - IEEE International Conference on Automation/23rd Congress of the Chilean Association of Automatic Control: Towards an Industry 4.0 Proceedings (2019)

8. S.Y. Eroshkin, N.A. Kameneva, D.V. Kovkov, A.I. Sukhorukov, Procedia Computer Science 103, 609-612 (2017) doi: 10.1016/j.procs.2017.01.079

9. S.Y. Eroshkin, A.I. Sukhorukov, N.D. Koryagin, D.V. Kovkov, D.V. Panov, Procedia Computer Science, 605-608 (2017) doi: 10.1016/j.procs.2017.01.076

10. X. Yusen, N.F. Bondaletova, V.I. Kovalev, A.V. Komrakov, 2018 Eleventh International Conference "Management of large-scale system development", MLSD (2018) doi: 10.1109/MLSD.2018.8551867 